Case Reports in
Gastroenterology
Case Rep Gastroenterol 2020;14:593-597

DOI: $10.1159 / 000508822$

Published online: November 2, 2020

(C) 2020 The Author(s)

Published by S. Karger AG, Basel

www.karger.com/crg

This article is licensed under the Creative Commons Attribution-NonCommercial 4.0 International License (CC BY-NC) (http://www.karger.com/Services/OpenAccessLicense) Usage and distribution for commercial purposes requires written permission.

\title{
Asymptomatic Colonic Anisakiasis: Is It So Rare?
}

\author{
Tetsuro Takasaki ${ }^{a}$ Toru Yamada ${ }^{b} \quad$ Junji Kinoshita ${ }^{a}$ Yasuaki Motomura $^{a}$ \\ aDepartment of Gastroenterology, Tokyo Bay Urayasu Ichikawa Medical Center, \\ Urayasu, Japan; bepartment of Family Medicine, Graduate School of Medical and Dental \\ Sciences, Tokyo Medical and Dental University, Tokyo, Japan
}

\section{Keywords}

Adult $\cdot$ Anisakis $\cdot$ Colon $\cdot$ Colonoscopy $\cdot$ Case report

\begin{abstract}
Most cases of anisakiasis occur in the stomach. Colonic anisakiasis, especially when asymptomatic, is extremely rare. We report a case of asymptomatic colonic anisakiasis and present a literature review of cases of colonic anisakiasis. A 52-year-old man underwent colonoscopy for colorectal cancer screening. Although no colorectal neoplasm was found, an Anisakis larva was detected in the transverse colon and the larva was removed by grasping forceps. Our review of PubMed revealed that $40 \%$ of cases of colonic anisakiasis are asymptomatic. We conclude that asymptomatic colonic anisakiasis may not be as rare as conventionally assumed.
\end{abstract}

\section{(C) 2020 The Author(s)}

Published by S. Karger AG, Basel

\section{Introduction}

Anisakiasis is a zoonotic infection most frequently caused by Anisakis simplex and Pseudoterranova decipiens. Marine mammals are the natural host, and humans can become 


\section{Case Reports in Gastroenterology}

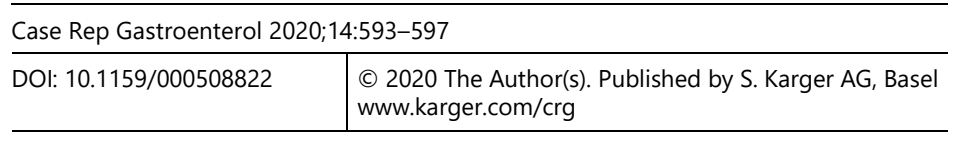

Takasaki et al.: Asymptomatic Colonic Anisakiasis: Is It So Rare?

incidental hosts by eating raw or undercooked seafood harboring Anisakidae larvae [1]. Anisakiasis is common in East Asia, especially in Japan, because of the dietary culture of eating raw fish. The stomach is the most common site of larval infection; the incidence of colonic anisakiasis is only $0.25 \%$ [2]. Without treatment, abdominal pain lasts from several weeks to 1 month, and more than half of colonic anisakiasis lesions are present on the right side [3]. Because of the nonspecific symptoms, such as abdominal pain, the differential diagnoses of symptomatic colonic anisakiasis are broad and include appendicitis, ileitis, diverticulitis, eosinophilic gastroenteritis, cholecystitis, colonic tumor, and inflammatory bowel disease [1]. Asymptomatic colonic anisakiasis is considered extremely rare [4, 5]. We report a case of asymptomatic anisakiasis and summarize previously reported cases of colonic anisakiasis regarding the presenting symptoms.

\section{Case Presentation}

A 52-year-old man underwent an immunochemical fecal occult blood test for a routine medical checkup at his local hospital. He had no symptoms and did not report eating any raw seafood. He was taking no medications. He had stopped smoking 1 year previously, but his alcohol consumption was in excess of $60 \mathrm{~g} /$ day. On physical examination, his temperature was $36.5^{\circ} \mathrm{C}\left(97.7^{\circ} \mathrm{F}\right)$, his blood pressure was $129 / 75 \mathrm{~mm} \mathrm{Hg}$, and his pulse rate was 75 beats $/ \mathrm{min}$. Abdominal examination revealed no masses or pain. Laboratory examinations were not performed because the patient was being screened specifically for colon cancer. The result of a fecal occult blood test was positive; consequently, he underwent colonoscopy, which identified an Anisakis nematode penetrating the wall of the transverse colon; the surrounding mucosa was slightly swollen (Fig. 1). The nematode was removed completely using grasping forceps, and no symptoms occurred following the colonoscopy.

\section{Discussion and Conclusion}

Asymptomatic colonic anisakiasis is considered rare because the number of case reports is low [5]. We reviewed previously reported cases of colonic anisakiasis in PubMed up to March 2019 using the keywords "Anisakis" and "colon" (Table 1) [2-15]. Papers that were not written in English and papers that contained no description of the patient's symptoms were excluded. Fourteen patients were identified; $6 / 15$ patients $(40.0 \%$, including our patient) were asymptomatic [3]. Among the 9 symptomatic patients, the most common symptom was abdominal pain ( $n=7,77.8 \%)$. The second most common symptoms were hematochezia $(n=$ $3,33.3 \%)$ and nausea $(n=3,33.3 \%)$. Our review showed that asymptomatic colonic anisakiasis may account for a large percentage of all cases of colonic anisakiasis beyond the conventional assumption. Notably, the main limitation of our study is the small number of cases, which occurred because most cases of anisakiasis are reported in Japanese.

The symptoms of anisakiasis are caused by the immune response to the Anisakis larvae. Anisakis larvae secrete potent proteolytic enzymes, called excretory-secretory products, to invade the gastrointestinal mucosa. The larval antigens, including the excretory-secretory products, induce allergic reactions. Anisakiasis is classified into three types according to the 


\section{Case Reports in Gastroenterology}

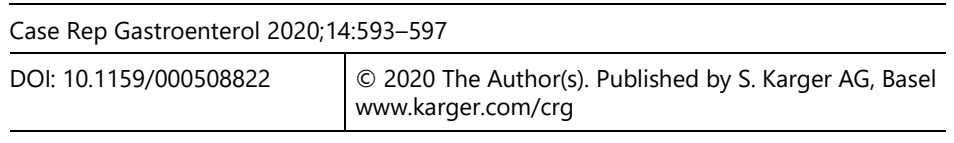

Takasaki et al.: Asymptomatic Colonic Anisakiasis: Is It So Rare?

immune response: indolent-type anisakiasis, which is caused by an innate immune response; fulminant-type anisakiasis, which is caused by hypersensitivity and induces severe symptoms; and chronic anisakiasis. Initial infection can cause an indolent-type allergic reaction with no or only mild symptoms [5], as in the present case. Anisakiasis should not be left untreated in asymptomatic patients. Chronic anisakiasis caused by degenerating larvae can lead to the development of an abscess and/or granuloma [1]. In some cases, a granuloma caused by Anisakis larvae needed differentiation from a tumor [6,7]. Complete removal of the larvae is strongly recommended when Anisakis is identified. Colonoscopy is not usually performed if a patient with colonic anisakiasis has no symptoms; therefore, asymptomatic colonic anisakiasis can be missed.

Anisakiasis rarely involves sites other than the stomach, and the incidence of asymptomatic colonic anisakiasis has been considered extremely low. However, our review of the worldwide literature showed that $40 \%$ of cases of colonic anisakiasis are asymptomatic. The consumption of raw fish has recently extended beyond Asia to become more globally widespread. As a result, we predict that the number of reports of asymptomatic colonic anisakiasis will increase.

\section{Acknowledgment}

We wish to acknowledge the assistance of Aki Miyagaki, Eriko Yamaguchi, Junji Kinoshita, Kento Fujioka, Risa Okamoto, and Tsubasa Yoshioka. We thank Jane Charbonneau, DVM, from Edanz Group (www.edanzediting.com/ac) for editing a draft of this paper.

\section{Statement of Ethics}

Written informed consent was obtained from the patient prior to the publication of this case report.

\section{Conflict of Interest Statement}

The authors have no competing interests to declare.

\section{Funding Sources}

The authors have no financial disclosures or funding to declare.

\section{Author Contributions}

T. Takasaki performed the literature review and wrote the manuscript. T. Yamada critically revised the manuscript and the literature review. J. Kinoshita performed the colonos- 


\section{Case Reports in Gastroenterology}

copy. Y. Motomura reviewed and assisted in writing the manuscript. All authors approved the final version of the manuscript.

\section{References}

1 Hochberg NS, Hamer DH. Anisakidosis: perils of the deep. Clin Infect Dis. 2010 Oct;51(7):806-12.

2 Mineta S, Shimanuki K, Sugiura A, Tsuchiya Y, Kaneko M, Sugiyama Y, et al. Chronic anisakiasis of the ascending colon associated with carcinoma. J Nippon Med Sch. 2006 Jun;73(3):169-74.

3 Tsukui M, Morimoto N, Kurata H, Sunada F. Asymptomatic anisakiasis of the colon incidentally diagnosed and treated during colonoscopy by retroflexion in the ascending colon. J Rural Med. 2016;11(2):73-5.

4 Zullo A, Balsamo G, Baldini D, Francesco V, Manta R. Asymptomatic Anisakis and erosive lesions in the colon. Ann Gastroenterol. 2018 Mar-Apr;31(2):246.

5 Taniguchi G, Nagahara A, Matsumoto K, Ritsuno H, Igusa Y, Sasaki H, et al. Asymptomatic anisakiasis of the colon incidentally found by colonoscopy. Clin J Gastroenterol. 2011 Dec;4(6):371-3.

6 Yorimitsu N, Hiraoka A, Utsunomiya H, Imai Y, Tatsukawa H, Tazuya N, et al. Colonic intussusception caused by anisakiasis: a case report and review of the literature. Intern Med. 2013;52(2):223-6.

7 Hernandez-Prera JC, Polydorides AD. Anisakidosis of the sigmoid colon disguising as metastatic carcinoma: a case report and review of the literature. Pathol Res Pract. 2012 Jul;208(7):433-5.

8 Mladineo I, Popović M, Drmić-Hofman I, Poljak V. A case report of Anisakis pegreffii (Nematoda, Anisakidae) identified from archival paraffin sections of a Croatian patient. BMC Infect Dis. 2016 Feb;16(1):42.

9 Cavallero S, Scribano D, D’Amelio S. First case report of invasive pseudoterranoviasis in Italy. Parasitol Int. 2016 Oct;65(5 5 Pt A):488-90.

10 Amir A, Ngui R, Ismail WH, Wong KT, Ong JS, Lim YA, et al. Anisakiasis causing acute dysentery in Malaysia. Am J Trop Med Hyg. 2016 Aug;95(2):410-2.

11 Kim SH, Park CW, Kim SK, Won S, Park WK, Kim HR, et al. A case of anisakiasis invading the stomach and the colon at the same time after eating anchovies. Clin Endosc. 2013 May;46(3):293-6.

12 Herranz-Bachiller MT, Atienza-Sánchez R, Barrio-Andrés J, Alcaide-Suárez N, Ruiz-Zorrilla R, Sancho-Del-Val L, et al. Colonic polyp secondary to Anisakis simplex. Rev Esp Enferm Dig. 2012 Oct-Nov;104(10):554-5.

13 Do KR, Cho YS, Kim HK, Hwang BH, Shin EJ, Jeong HB, et al. Intestinal helminthic infections diagnosed by colonoscopy in a regional hospital during 2001-2008. Korean J Parasitol. 2010 Mar;48(1):75-8.

14 Higashi M, Tanaka K, Kitada T, Nakatake K, Tsuji M. Anisakiasis confirmed by radiography of the large intestine. Gastrointest Radiol. 1988;13(1):85-6.

15 Matsui T, Iida M, Murakami M, Kimura Y, Fujishima M, Yao Y, et al. Intestinal anisakiasis: clinical and radiologic features. Radiology. 1985 Nov;157(2):299-302. 


\section{Case Reports in Gastroenterology}

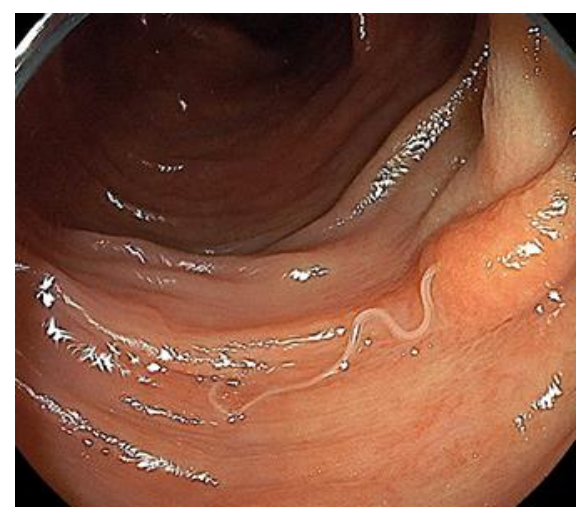

Fig. 1. A 52-year-old man underwent colonoscopy during a routine medical checkup. An Anisakis larva was observed in the transverse colon.

Table 1. Published cases of colonic anisakiasis

\begin{tabular}{|c|c|c|c|c|c|c|}
\hline $\begin{array}{l}\text { Case } \\
\text { No. }\end{array}$ & Year & $\begin{array}{l}\text { Age, years/ } \\
\text { sex }\end{array}$ & Country & Detection site & Symptoms & Ref. \\
\hline 1 & 2018 & $50 / \mathrm{M}$ & Italy & sigmoid colon & none & 4 \\
\hline 2 & 2016 & $74 / \mathrm{M}$ & Japan & ascending colon & none & 3 \\
\hline 3 & 2016 & $65 / F$ & Italy & ascending colon & nonspecific symptoms & 8 \\
\hline 4 & 2016 & $64 / \mathrm{M}$ & Malaysia & ascending colon & abdominal discomfort, hematochezia & 9 \\
\hline 5 & 2016 & $70 / \mathrm{F}$ & Croatia & sigmoid colon & abdominal pain, nausea & 10 \\
\hline 6 & 2013 & $47 / \mathrm{M}$ & Korea & transverse colon & abdominal pain, nausea & 11 \\
\hline 7 & 2013 & $67 / F$ & Japan & ascending colon & abdominal pain & 7 \\
\hline 8 & 2012 & $47 / F$ & Spain & rectum & hematochezia & 12 \\
\hline 9 & 2012 & $45 / \mathrm{F}$ & USA & sigmoid colon & hematochezia, anemia & 6 \\
\hline 10 & 2011 & $42 / \mathrm{M}$ & Japan & ascending colon & none & 5 \\
\hline 11 & 2010 & $49 / \mathrm{M}$ & Korea & ascending colon & none & 13 \\
\hline 12 & 2006 & $69 / \mathrm{M}$ & Japan & ascending colon & abdominal pain, diarrhea, urticaria & 2 \\
\hline 13 & 1988 & $37 / \mathrm{M}$ & Japan & ascending colon & abdominal pain, nausea, vomiting & 14 \\
\hline 14 & 1985 & $62 / F$ & Japan & ascending colon & abdominal pain & 15 \\
\hline
\end{tabular}

M, male; F, female. 